A N N A L E S Annales de Bretagne et des Pays de l'Ouest

Jacqueline CAILLE, Medieval Narbonne, a city at the heart of the troubadour world

\title{
André Chédeville
}

\section{(2) OpenEdition}

\section{Journals}

Édition électronique

URL : http://journals.openedition.org/abpo/563

DOI : $10.4000 / a b p o .563$

ISBN : 978-2-7535-1504-8

ISSN : 2108-6443

Éditeur

Presses universitaires de Rennes

Édition imprimée

Date de publication : 30 décembre 2006

Pagination : 201-202

ISBN : 978-2-7535-0405-9

ISSN : 0399-0826

Référence électronique

André Chédeville, "Jacqueline Callte, Medieval Narbonne, a city at the heart of the troubadour world », Annales de Bretagne et des Pays de l'Ouest [En ligne], 113-4 | 2006, mis en ligne le 30 décembre 2008 , consulté le 23 septembre 2020. URL : http://journals.openedition.org/abpo/563 ; DOI : https://doi.org/ 10.4000/abpo.563

Ce document a été généré automatiquement le 23 septembre 2020

(c) Presses universitaires de Rennes 


\title{
Jacqueline CAILLE, Medieval Narbonne, a city at the heart of the troubadour world
}

\author{
André Chédeville
}

\section{RÉFÉRENCE}

éd. K. L. Reyerson, Aldershot-Burlington/Ashgate variorum, 2005, XXVI + 388 p.

1 Ce volume, agréablement présenté, offre une série d'études de la spécialiste de l'histoire de Narbonne au Moyen Âge. Il ne contient pas seulement des reprints avec leur mise en page et leur typographie spécifiques d'où l'absence d'une pagination continue. Certains articles ont été traduits en anglais sans que l'on connaisse la raison de ce choix. Surtout, l'ouvrage s'ouvre sur un survol inédit, en anglais, de l'histoire de Narbonne des origines à la fin $\mathrm{du} \mathrm{xv}^{\mathrm{e}}$ siècle qui insiste particulièrement sur la période $\mathrm{XI}^{\mathrm{e}}$-XIII ${ }^{\mathrm{e}}$ siècles, la plus brillante des siècles médiévaux, celle aussi qui fait l'objet des quatorze études qui suivent.

2 Les premières envisagent le développement de l'agglomération. Fondée en 118 avant J.C., capitale des Wisigoths pendant deux décennies au vie siècle, principale cité de Gaule aux mains des Musulmans de 715 ou 719 à 759, puis dorénavant centre d'une province ecclésiastique dont les archevêques doivent composer avec les seigneurs laïques puissants bien que simples vicomtes, Narbonne connaît un essor topographique dès avant l'an mil. En 990, sont mentionnés les bourgs de Coyran et de Villeneuve au pied des murs de la cité, en bordure de l'Aude où se trouve le port. Puis, sur la rive droite de l'Aude, reliée par un pont romain apparaît le Bourg qui dut avoir pour noyau primitif l'abbaye Saint-Paul mais qui grandit grâce au carrefour de la via Domitia, qui menait aussi bien vers l'Italie que vers l'Espagne, avec la via Aquitania qui se dirigeait vers le nord. Au début du XII ${ }^{\mathrm{e}}$ siècle, le Bourg est doté d'une muraille qui enclot un peu plus de 15 hectares soit à peine moins que la superficie de la Cité. On a ainsi un très bel exemple 
de ville double dont chaque partie dispose de l'ensemble des éléments nécessaires à la vie urbaine, encore que l'archevêque et le vicomte résident tous deux dans la Cité. C'est à ce moment que s'individualisent les paroisses urbaines dont l'auteur réussit à préciser l'historique et les limites : un siècle plus tard, elles sont toutes en place au nombre de huit, six pour la Cité et deux pour le bourg.

Un tel essor s'explique par le dynamisme de l'économie qui ne s'était jamais complètement assoupie. Elle repose d'abord sur l'industrie du cuir et surtout sur celle des draps de laine mais elle a dépassé le stade de l'auto-consommation grâce à la situation de la ville ouverte aussi bien sur la Méditerranée par son port que sur l'arrière-pays et au-delà par un réseau de voies anciennes et nouvelles. Centre de production, elle devient bientôt également un centre de distribution pour tous les produits venus de la péninsule ibérique, d'Afrique du nord, d'Italie et même d'Orient. Les relations commerciales sont confortées par des accords avec les cités concurrentes, le premier avec Montpellier en 1079, puis avec Gênes en 1132, Pise en 1167, etc. Toute cette activité explique en partie le maintien d'une importante communauté juive engagée surtout dans le commerce de l'argent, célèbre aussi par la science de ses docteurs. Enrichis et ouverts au monde, les Narbonnais au XII siècle obtiennent des vicomtes, plus souvent que des archevêques, des consuls qui apparaissent d'abord lors de la conclusion des accords commerciaux ou de la fondation ou de la gestion des établissements hospitaliers de la ville. En 1205 enfin, huit consuls, quatre pour la Cité et quatre pour le Bourg, commencent de participer à la gestion municipale; en même temps, le terme universitas, caractéristique d'un esprit communautaire, l'emporte peu à peu sur celui, classique, de populus. Ayant échappé aux ravages de la croisade albigeoise, Narbonne continue de se développer pour atteindre sans doute 30000 habitants au milieu du XIV siècle, chiffre que la ville ne va retrouver qu'à la fin du XIX siècle. Narbonne a en effet beaucoup souffert de la crise de la fin du Moyen Âge, crise aggravée par la concurrence victorieuse de Montpellier. Les deux villes ont connu le même essor rapide et se sont dotées des mêmes infrastructures mais la seconde l'a emporté parce qu'elle était plus proche du grand axe rhodanien, parce que les Italiens ont préféré s'y installer enfin et peut-être surtout parce que les bourgeois de Montpellier étaient soumis à une tutelle seigneuriale moins pesante et moins coûteuse que celle de leurs voisins.

D'autres études confortent des recherches plus récentes qui ont prouvé l'existence en Languedoc dès le $\mathrm{XI}^{\mathrm{e}}$ siècle à la fois de la seigneurie et de la féodalité. Elles s'appuient sur l'analyse d'une part du pouvoir temporel des archevêques et d'autre part de la politique de la famille vicomtale au $\mathrm{xII}^{\mathrm{e}}$ siècle. Parmi ses membres, se détache Ermengarde qui, encore mineure, hérite de Narbonne et de la vicomté en 1134. Veuve vers 1157 puis sous la tutelle de son lignage, elle administre elle-même sa vicomté pendant dix ans après 1179. Elle sait se faire obéir de ses vassaux et réussit à maintenir l'équilibre entre les deux puissances voisines: les comtes de Barcelone et ceux de Toulouse. Curieusement, on ignore comment après 1192 son neveu Pierre de Lara lui succéde ni quand et où précisément elle meurt en exil, sans doute peu après 1196. Elle passe pour avoir entretenu à sa cour de nombreux troubadours, ce qui justifie le soustitre de ce livre; on lui a même prêté une idylle avec le prince, poète et musicien Rognvald Kali des Orcades qui, en 1152, aurait relâché à Narbonne en faisant voile vers la Terre Sainte... 
5 Nous sommes là bien loin de nos villes de l'Ouest : c'est une occasion de découvrir ou d'examiner en détail la monumentalité, les institutions et l'économie d'un grand centre méditerranéen. Pourtant, les destinées humaines peuvent présenter des traits communs; l'auteur elle-même établit un parallèle avec Aliénor d'Aquitaine qui sut gouverner, qui eut aussi sa cour de poètes et qui connut également le malheur du temps de son époux Henri II comme à la fin de sa vie. Elle eût pu évoquer tout autant la duchesse Constance de Bretagne qui, elle aussi, à la même époque, dut résister au même Henri II et à ses fils. 